\author{
Stanisław GACA ${ }^{1}$ \\ Mariusz KIEĆ
}

\title{
METODA POŚREDNIEJ OCENY BEZPIECZEŃSTWA PIESZYCH NA PRZEJŚCIACH
}

\begin{abstract}
W analizach bezpieczeństwa ruchu drogowego coraz większą rolę odgrywają pośrednie miary bezpieczeństwa, w tym prędkość pojazdów. W nawiązaniu do tego trendu badań autorzy przedstawili koncepcję modelu pośredniego szacowania prawdopodobieństwa wypadków najechania na pieszego w obrębie wyznaczonych przejść. Wykorzystując dane o prędkości pojazdów z pomiarów empirycznych na terenach zurbanizowanych, porównano potencjalne zagrożenia bezpieczeństwa pieszych na przejściach o różnych lokalizacjach i rozwiązaniach geometrycznych. W porównaniach tych oceniano możliwości zatrzymania się pojazdu przed pieszym w przypadkach jego wtargnięcia na przejście.
\end{abstract}

Słowa kluczowe: bezpieczeństwo ruchu, pieszy, przejście dla pieszych, prędkość, pośrednia miara bezpieczeństwa

\section{Wprowadzenie}

Piesi należą do najbardziej zagrożonych grup użytkowników dróg w Polsce. W porównaniu do innych krajów Unii Europejskiej w Polsce rejestruje się jeden z największych wskaźników demograficznych ofiar śmiertelnych wypadków drogowych z udziałem pieszych [5]. Duża część tych wypadków ma miejsce na wyznaczonych przejściach dla pieszych, które z założenia powinny zapewniać jak najlepsze warunki bezpieczeństwa ruchu. Wbrew oczekiwaniom, w latach 2013 - 2015 wystąpił wzrost udziału wypadków na przejściach dla pieszych w zbiorze wszystkich wypadków z pieszymi, od 35,8\% w roku 2013 do 40,9\% w roku 2015 [7]. Na przejściach dla pieszych w latach 2013 - 2015 liczba ofiar śmiertelnych wyniosła ok. $25 \%$ ogółu ofiar śmiertelnych wśród pieszych.

Przyczyny niezwykle dużego zagrożenia bezpieczeństwa pieszych na wyznaczonych przejściach nie są łatwe do kwantyfikacji m.in. z powodu złożoności

\footnotetext{
${ }^{1}$ Autor do korespondencji/corresponding author: Stanisław Gaca, Politechnika Krakowska, Katedra Budowy Dróg i Inżynierii Ruchu, ul. Warszawska 24, 31-155 Kraków, 12 6282320, sgaca@ pk.edu.pl ${ }^{2}$ Mariusz Kieć, Politechnika Krakowska, Katedra Budowy Dróg i Inżynierii Ruchu, ul. Warszawska 24, 31-155 Kraków, 12 6282158, mkiec@ pk.edu.pl
} 
czynników determinujących ryzyko wypadków z udziałem pieszych. Można wskazać co najmniej na 5 grup czynników, tj. związane z: kierującymi pojazdami, drogą i jej otoczeniem, pojazdami i ich ruchem, uwarunkowaniami demograficznymi i społeczno-ekonomicznymi oraz charakterystyką pieszych jako uczestników ruchu $[5,8]$. Rola tych czynników może ujawniać się w różnym stopniu, w zależności od konfiguracji ich występowania i lokalnych uwarunkowań. Taka złożoność roli wspomnianych czynników, wraz z bardzo dużą liczbą ich charakterystyk opisowych powodują, że w celu kwantyfikacji ich wpływu poszukuje się bardziej efektywnych metod niż często stosowane modele regresyjne. Modele te zwykle w niewystarczającym stopniu uwzględniają lokalne uwarunkowania bezpieczeństwa ruchu oraz nietypowe rozwiązania drogowe.

Nowe możliwości wielostronnej oceny zagrożeń bezpieczeństwa pieszych na wyznaczonych przejściach oferują metody badań wykorzystujące, tzw. miary pośrednie bezpieczeństwa ruchu. Najbardziej znanymi miarami pośrednimi są konflikty w ruchu drogowym, rozumiane jako sytuacje, w których uczestnicy ruchu zbliżają się do siebie w przestrzeni i w czasie w taki sposób, że zdarzenie drogowe jest bardzo prawdopodobne, jeżeli ich sposób poruszania się pozostanie bez zmian. Konflikty mogą być identyfikowane za pomocą parametrów opisujących, np.: odległości pomiędzy uczestnikami ruchu w sytuacjach występowania incydentów; manewry opóźnień lub przyspieszeń wykonywane w celu uniknięcia konfliktu; gwałtowne zmiany toru jazdy itp. [1,3,4]. Pośrednią miarą oceny zagrożeń bezpieczeństwa ruchu może być także prędkość pojazdów w sytuacjach potencjalnego wystąpienia incydentów w ruchu.

Pośrednie miary oceny bezpieczeństwa ruchu z reguły są dobierane tak, aby nawiązywały do ogólnego modelu ryzyka opisanego wzorem:

$$
R W_{i}=R_{W} \cdot P_{Z i} \cdot P_{C i}
$$

gdzie: $R W_{i}-$ miara ryzyka wypadków $i$-tego rodzaju,

$R_{W}$ - miara wystawienia na ryzyko, np. natężenie ruchu, liczba incydentów w przyjętej jednostce czasu,

$P_{Z i}$ - prawdopodobieństwo wystąpienia zdarzenia $i$-tego rodzaju w odniesieniu do jednostki miary wystawienia na ryzyko,

$P_{C i}$ - prawdopodobieństwo wystąpienia określonego stopnia ciężkości zdarzenia drogowego (skutku zdarzenia) $i$-tego rodzaju.

Przy takim opisie ryzyka wypadków łatwo dostrzec, że miary pośrednie, w zależności od ich wyboru, mogą opisywać wystawienie na ryzyko, prawdopodobieństwo zdarzenia drogowego lub jego skutki. W przypadku wyboru prędkości pojazdów jako miary pośredniej, jej charakterystyki mogą się odnosić zarówno do prawdopodobieństwa określonych skutków zdarzenia, jak i prawdopodobieństwa samego wystąpienia określonej sytuacji w ruchu drogowym. Takie ujęcie wpływu prędkości wykorzystano w zbudowanym przez autorów modelu 
kinematyczno-probabilistycznym oceny bezpieczeństwa pieszych na wyznaczonych przejściach [2]. Wykorzystując ten model porównano potencjalne zagrożenia bezpieczeństwa pieszych na przejściach o różnych lokalizacjach, przekrojach poprzecznych drogi i rozwiązaniach geometrycznych.

\section{Model oceny bezpieczeństwa pieszych na przejściach}

Podstawowym parametrem wpływającym na prawdopodobieństwo śmierci pieszego w wyniku uderzenia w niego pojazdu jest prędkość. Ilościowe oszacowanie tego prawdopodobieństwa nie jest jednoznaczne, co ilustrują przykłady wyników badań pokazane na rys. 1 .
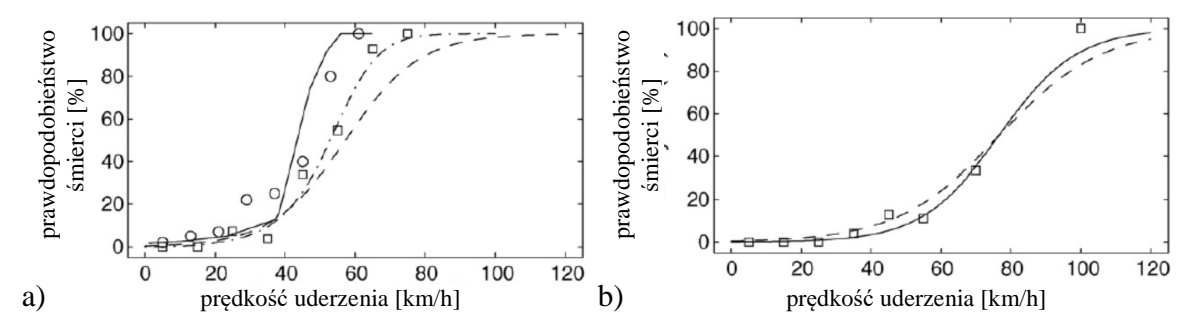

Rys. 1. Prawdopodobieństwo śmierci pieszego w zależności od prędkości uderzenia pojazdu, na podstawie [6]

Fig. 1. Relationship of pedestrian fatality risk and impact speed, based on [6]

Przy podanym zastrzeżeniu można stwierdzić, że korzystając z dostępnych zależności zilustrowanych na rys. $1 \mathrm{~b}$ i znając dodatkowo prędkości pojazdów na dojeździe do przejścia dla pieszych w sytuacjach konfliktowych (np. wtargnięcie pieszego na przejście), możliwe jest szacowanie prawdopodobieństwa śmierci pieszych w takich sytuacjach. Ryzyko wypadków wyrażone prawdopodobną liczbą ofiar śmiertelnych pieszych $L W_{P S}$ może być szacowane na podstawie ogólnie zapisanej zależności:

$$
L W_{P S}=\sum_{i} R_{W i}\left(V_{i}\right) \cdot P_{i}\left(V_{0 i}\right)
$$

gdzie: $R_{W i}(V i)$ - wystawienie na ryzyko opisywane liczbą konfliktów „,pojazdpieszy" w sytuacji dojazdu pojazdu z prędkością $V_{i}$, $P_{i}\left(V_{0 i}\right)$ - prawdopodobieństwo śmierci pieszego w wyniku uderzenia w niego przez pojazd z prędkością $V_{0}$ wynikającą z prędkości dojazdu $V_{i}$.

Pełną interpretację zależności opisanej wzorem (2) wraz z jej uszczegółowieniem zamieszczono w [2]. W artykule autorzy pragną zwrócić uwagę na istotną rolę prędkości uderzenia pojazdu w pieszego $V_{0}$, która może być obliczona ze wzoru: 


$$
V_{0}=\sqrt{2 \cdot a \cdot\left(V_{i} \cdot t_{r}-L\right)+V_{i}^{2}} \quad[\mathrm{~m} / \mathrm{s}]
$$

gdzie: $a$ - opóźnienie w czasie hamowania $\left[\mathrm{m} / \mathrm{s}^{2}\right]$,

$t_{r}$ - czas reakcji kierującego pojazdem [s],

$L$ - odległość, z której kierujący pojazdem zauważa pieszego [m],

$V_{0}, V_{i}-$ jak we wzorze (2) $[\mathrm{m} / \mathrm{s}]$.

Korzystając ze wzoru (3) wyznaczono potencjalne wartości prędkości uderzenia $\mathrm{w}$ pieszego $\mathrm{w}$ zależności od prędkości pojazdu w różnych odległościach od przejścia w zakresie od 10 do 50m (rys. 2).

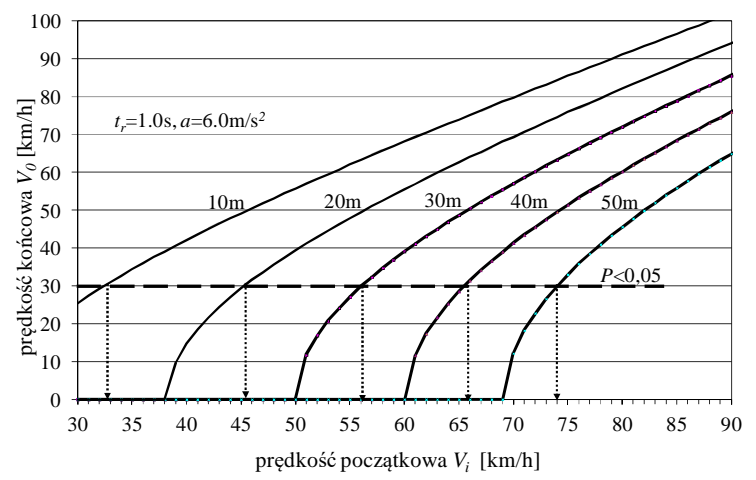

Rys. 2. Zależność potencjalnej prędkości zderzenia z pieszym od odległości podjęcia manewru hamowania i prędkości początkowej pojazdu

Fig. 2. Relationship between vehicle speed during collision with pedestrian and distance where driver noticed pedestrian

Na podstawie rys. 2 można szacować występującą we wzorze (2) prędkość $V_{0 i}$ przy dowolnej wartości prędkości $V_{i}$ przed przejściem. Jako szczególny przypadek wyróżniono sytuacje, w których kierujący pojazdem może się zatrzymać przed pieszym $\left(V_{0 i}=0\right)$ - brak zdarzenia drogowego. Dysponując dystrybuantą rozkładu prędkości przed przejściem można szacować udział kierujących pojazdami, którzy mogą się zatrzymać przed pieszymi w sytuacjach konfliktowych $-F\left(V_{0}=0\right)$. Analizując różne przypadki zachowywania się kierujących pojazdami (np. różne przejścia, różne odległości dostrzegania pieszych) wyznacza się iloraz $H R$ (wzór 4) przypisanych tym sytuacjom wartości $F\left(V_{0}\right)$. Wartość tego ilorazu jest relatywną, pośrednią oceną szczególnego przypadku porównania bezpieczeństwa pieszych na przejściach w różnych sytuacjach. Poszerzony zakres takich porównań wraz z walidacją modelu opisano w [2].

$$
H R=\frac{F\left(V_{0}\right)_{A}}{F\left(V_{0}\right)_{B}} \quad[-]
$$


gdzie: $F\left(V_{0}\right)_{A}$ i $F\left(V_{0}\right)_{B}$ - wartości dystrybuanty prędkości dla danego prawdopodobieństwa śmierci pieszego w sytuacjach A i B (B - referencyjna).

Do oceny zmian poziomu bezpieczeństwa na przejściu dla pieszych w opisywanym przypadku wykorzystano iloraz prawdopodobieństwa wystąpienia sytuacji gdy pojazd zatrzyma się przed przejściem $\left(V_{0}=0 \mathrm{~km} / \mathrm{h}\right)$ lub osiąga relatywnie bezpieczną prędkość ( $30 \mathrm{~km} / \mathrm{h}$, co oznacza $P_{i}<0,05 \mathrm{wg}$ rys. $1 \mathrm{~b}$ i 2$)$.

\section{Empiryczne pomiary prędkości przed przejściami}

Pomiary prędkości pojazdów były realizowane z wykorzystaniem rejestracji obrazu z kamer wideo, o dużej rozdzielczości, umieszczonych na maszcie o zmiennej wysokości od 5 do $7 \mathrm{~m}$. Rejestracji podlegał ruch pojazdów na odcinku drogi na dojeździe do przejścia dla pieszych oraz zachowania pieszych w sąsiedztwie przejścia. W zależności od poligonu badawczego do rejestracji obrazu wykorzystywano jedną lub dwie kamery wideo zamocowane do masztu ustawionego w odległości około 10-15m za przejściem dla pieszych.

Pomiarami objęto pojazdy jadące w kierunku przejścia dla pieszych. Maksymalny zasięg rejestracji obrazu wynosił $100 \mathrm{~m}$. W trakcie realizacji pomiaru w terenie wyznaczono przekroje pomiarowe co $20 \mathrm{~m}$, stanowiące bazę pomiarową do oceny prędkości średniej. Długość bazy pomiarowej dobrano tak, aby minimalny czas przejazdu odcinka wynosił ok. 1 sekundy, co pozwoliło zminimalizować błędy obserwatorów rejestrujących zdarzenia w trakcie analizy obrazu wideo. Prędkość w przekrojach pośrednich wyznaczono jako wartość średnią, zakładając ruch jednostajny pojazdów pomiędzy przekrojami.

W pomiarach prędkości uwzględniono wyłącznie pojazdy poruszające się w ruchu swobodnym na odcinku $100 \mathrm{~m}$ przed przejściem. Analizowano tylko sytuacje braku występowania pieszego na przejściu zakładając, że w przypadku jego występowania zwiększa się stopień koncentracji kierującego pojazdem, co skutkuje zmianą jego zachowania i skróceniem czasu reakcji. Na podstawie wykonanych pomiarów uzyskano dane o dystrybuantach rozkładów prędkości pojazdów na dojazdach do 5 różnych typów przejść dla pieszych.

\section{Dyskusja wyników}

Przedstawiona metodyka pośredniej oceny bezpieczeństwa ruchu została zastosowana do porównań potencjalnych skutków wypadków w sytuacjach potencjalnego wtargnięcia pieszego na jezdnię. Analizowano następujące przypadki:

- różne lokalizacje przejść (duże miasto, mała miejscowość),

- różne przekroje poprzeczne drogi (przekrój dwujezdniowy dwupasowy 2x2, przekrój jednojezdniowy dwupasowy 1x2),

- występowanie wyspy azylu dla pieszych,

- zmiany prędkości wraz ze zbliżaniem się pojazdów do przejścia. 
W tabeli nr 1 zestawiono wartości dystrybuanty prędkości $\left.F\left(V_{0}\right)\right)$ odpowiadające prawdopodobieństwu śmierci pieszego $P_{i}=0$ (pojazd się zatrzyma) i $P_{i}<0,05$, przy zmieniającej się prędkości w odległościach $50 \mathrm{~m}, 40 \mathrm{~m}, 30 \mathrm{~m}, 20 \mathrm{~m}$ i $10 \mathrm{~m}$ od przejścia. Wartości zestawione w tabeli 1 wskazują jaki procent kierujących pojazdami jest $\mathrm{w}$ stanie zatrzymać się przed przejściem lub najechać na pieszego z prędkością nie większą niż $30 \mathrm{~km} / \mathrm{h}$. Na podstawie tych wyników obliczono wartość relatywnego wskaźnika $H R$ względem przejścia referencyjnego (ulica 1x2, przejście $\mathrm{z}$ wyspą azylu) uznawanego za potencjalnie najbezpieczniejsze spośród analizowanych.

Tabela 1. Zestawienie wartości dystrybuanty prędkości $F\left(V_{0}\right)$ na różnych poligonach

Table 1. Values of speed distribution $F\left(V_{0}\right)$ for various measurement sites

\begin{tabular}{|c|c|c|c|c|c|c|}
\hline \multirow{2}{*}{ Lokalizacja } & \multirow{2}{*}{ Przekrój } & \multicolumn{5}{|c|}{ Odległość od przejścia dla pieszych } \\
\hline & & $10 \mathrm{~m}$ & $20 \mathrm{~m}$ & $30 \mathrm{~m}$ & $40 \mathrm{~m}$ & $50 \mathrm{~m}$ \\
\hline \multicolumn{7}{|c|}{$P_{i}=0$ (pojazd zatrzyma się przed przejściem) } \\
\hline \multirow{4}{*}{ Miasto } & $1 \times 2 M$ azyl & $-^{*}$ & 0,283 & 0,913 & 1,000 & 1,000 \\
\hline & $1 \times 2 \mathrm{M}$ & $-{ }^{*}$ & 0,310 & 0,913 & 0,984 & 1,000 \\
\hline & $2 \times 2 M$ pas $L$ & $-{ }^{*}$ & 0,020 & 0,163 & 0,624 & 0,870 \\
\hline & $2 \times 2 \mathrm{M}$ pas $\mathrm{P}$ & $-{ }^{*}$ & 0,072 & 0,278 & 0,767 & 0,937 \\
\hline \multirow{2}{*}{ Miejscowość } & $1 \times 2 \mathrm{P}$ & $-{ }^{*}$ & 0,000 & 0,189 & 0,554 & 0,876 \\
\hline & $1 \mathrm{x} 2 \mathrm{P}$ azyl & $-{ }^{*}$ & 0,026 & 0,057 & 0,247 & 0,692 \\
\hline \multicolumn{7}{|c|}{$P_{i}=0,05($ pojazd uderzy w pieszego z prędkością poniżej $30 \mathrm{~km} / \mathrm{h})$} \\
\hline \multirow{4}{*}{ Miasto } & $1 \times 2 \mathrm{M}$ azyl & 0,174 & 0,739 & 1,000 & 1,000 & 1,000 \\
\hline & $1 \mathrm{x} 2 \mathrm{M}$ & 0,084 & 0,668 & 0,979 & 0,996 & 1,000 \\
\hline & $2 \times 2 \mathrm{M}$ pas $\mathrm{L}$ & 0,015 & 0,103 & 0,407 & 0,811 & 0,946 \\
\hline & $2 \mathrm{x} 2 \mathrm{M}$ pas $\mathrm{P}$ & 0,049 & 0,228 & 0,613 & 0,908 & 0,971 \\
\hline \multirow{2}{*}{ Miejscowość } & $1 \times 2 \mathrm{P}$ & 0,000 & 0,092 & 0,411 & 0,792 & 0,892 \\
\hline & 1x2P azyl & 0,007 & 0,051 & 0,152 & 0,516 & 0,876 \\
\hline
\end{tabular}

- brak możliwości zatrzymania się pojazdu przed przejściem

Na rys. 3 przedstawiono oszacowane zwiększenie zagrożenia pieszych na różnych przejściach, oceniane jako procent pojazdów, które nie zatrzymają się $\left(P_{i}=0\right)$ lub mogą uderzyć w pieszego z prędkością większą niż $30 \mathrm{~km} / \mathrm{h}$ $\left(P_{i}<0,05\right)$, względem referencyjnego przejścia. Pokazana na rysunku wartość wskaźnika wzrostu zagrożenia została wyznaczona jako: $(1,0-H R) * 100 \%$.

$\mathrm{Z}$ analizy danych przedstawionych na rysunku 3 wynika, że:

- najbardziej niebezpieczne przejścia, o podobnym poziomie bezpieczeństwa, występują na odcinkach przejść drogowych przez miejscowości,

- przejścia dla pieszych na odcinkach o przekroju 2x2 są bardziej niebezpieczne w mieście, w szczególności w obrębie lewego pasa ruchu,

- brak azylu dla pieszych powoduje 2-krotne zwiększenie udziału kierujących pojazdami w mieście, którzy mogą najechać na pieszych z prędkością większą niż $30 \mathrm{~km} / \mathrm{h}$, w przypadku ich zauważenia z odległości 10m, 
- poprawa stopnia przestrzegania ograniczeń prędkości wpływa na poprawę bezpieczeństwa pieszych. Poruszanie się z prędkością $60 \mathrm{~km} / \mathrm{h}$ w odległości $40 \mathrm{~m}$ od przejścia dla pieszych umożliwia zatrzymanie pojazdu w sytuacji konfliktu z pieszym po podjęciu manewru hamowania z opóźnieniem $6 \mathrm{~m} / \mathrm{s}^{2}$ i większym.
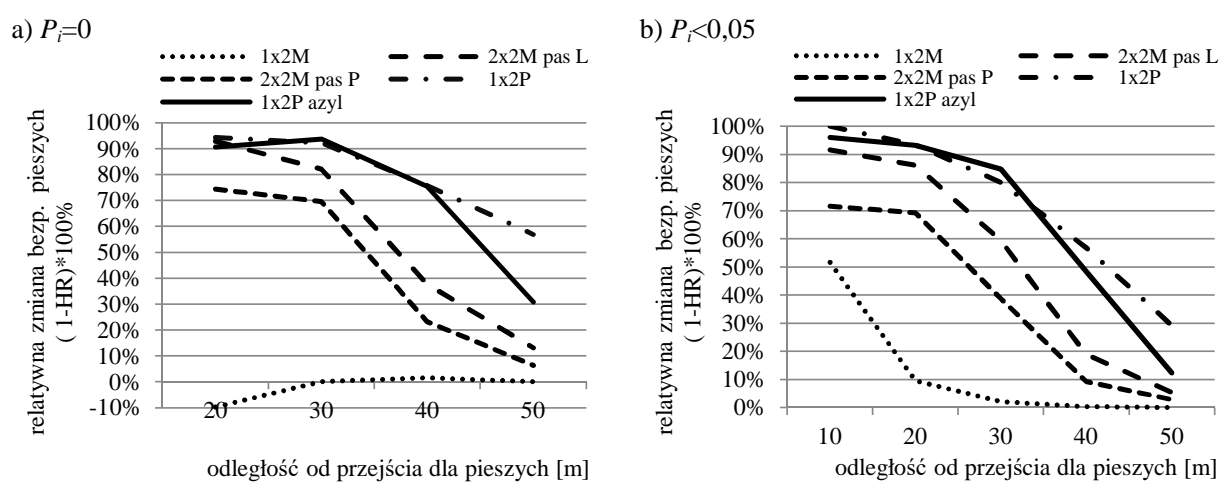

Rys. 3. Relatywna zmiana bezpieczeństwa pieszych na różnych poligonach badawczych

Fig. 3. Relative change of pedestrian safety for various measurement sites

\section{Podsumowanie}

Przy interpretacji wyników szacowania zmian bezpieczeństwa pieszych na podstawie opisanego modelu należy brać pod uwagę następujące ograniczenia wynikające z przyjętych założeń:

- wartości czasu reakcji kierujących pojazdami są uśrednione i nie zmieniają się w czasie. W rzeczywistości mogą się one zmieniać w czasie, co będzie powodować także zmiany poziomu szacowanego zagrożenia bezpieczeństwa pieszych;

- przyjęta funkcja prawdopodobieństwa śmierci pieszego reprezentuje uśrednione wartości ryzyka (dla $\left.P_{i}<0,05\right)$;

- prawdopodobieństwo błędu pieszego (wtargnięcie na przejście) jest takie samo na porównywanych przejściach; W rzeczywistości może się ono zmieniać pod wpływem lokalnych czynników.

Przedstawiona metoda, poza prostymi porównaniami wpływu typu przejść, może być użyteczna również do badań wpływu ograniczeń widoczności, stanu nawierzchni oraz środków zarządzania prędkością na zmiany bezpieczeństwa pieszych w tych samych miejscach.

Zastosowanie opisanej metody do kwantyfikacji liczby pieszych, którzy mogą stać się ofiarą zdarzenia drogowego wymaga jej uzupełnienia o moduł szacowania prawdopodobieństwa błędu pieszego i pojawiania się dodatkowych interakcji „,kierujący pojazdem - pieszy” zmieniających wzajemne zachowania. 


\section{Literatura}

[1] FHWA Report, Surrogate Safety Assessment Model and Validation: Final Report, Federal Highway Administration, FHWA-HRT-08-051, 2008.

[2] Gaca S., Kiec M., Assessment of Pedestrian Risk at Crossings with KinematicProbabilistic Model, Transportation Research Record: Journal of the Transportation Research Board, vol. 2514, 2015, pp 129-137.

[2] Kieć M., Zastosowanie techniki konfliktów ruchowych jako miary pośredniej w ocenie bezpieczeństwa ruchu drogowego, Logistyka, 6/2014, s. 5395-5404.

[4] Laureshyn A, Svensson A, Hydén C., Evaluation of traffic safety, based on microlevel behavioural data: theoretical framework and first implementation. Accident Analysis \& Prevention, Volume 42, 2010, pp 1637-1646.

[5] Podręcznik ochrony pieszych dla instytucji zarządzających bezpieczeństwem ruchu drogowego i zarządów dróg, Fundacja Rozwoju Inżynierii Lądowej - Politechnika Gdańska - Politechnika Krakowska, Gdańsk/Warszawa 2014.

[6] Rosén E, Sander U. and Stigson H., Literature review of pedestrian fatality risk as a function of car impast speed. Accident Analysis and Prevention, Vol. 43, 2011, pp. 25-33.

[7] Wypadki drogowe w Polsce, Wydział Ruchu Drogowego Biura Prewencji i Ruchu Drogowego Komendy Głównej Policji, Warszawa 2013, 2014, 2015.

[8] Zegeer C.V., Bushell M., Pedestrian crash trends and potential countermeasures from around the world. Accident Analysis \& Prevention, Vol. 44, 2012, pp. 3-11.

\section{ASSESSMENT OF PEDESTRIAN SAFETY AT PEDESTRIAN CROSSINGS BASED ON VEHICLES SPEEDS}

\section{S u m m a r y}

In road safety analyses, surrogate safety measures, including speed of vehicles, play an increasingly important role. In relation to this trend, the authors presented the concept of model for indirectly estimation probability of accidents, hitting in pedestrian, at marked pedestrian crossing. Potential hazards at pedestrian crossings for various locations and geometric designing based on empirical research speed of vehicles in urban areas were compared. The possibility of stopping vehicles in front of pedestrians, in case of their intrusion at pedestrian crossing, were evaluated.

Keywords: road safety, pedestrian, pedestrian crossings; speed; surrogate safety measure

Przestano do redakcji: 07.06.2016 $r$.

Przyjęto do druku: 30.06.2016 r.

DOI: $10.7862 / \mathrm{rb} .2016 .76$ 